\title{
Expression Mechanism of Chinese Visual Experience-Taking the Historical Evolvement and Extraterritorial Construction of the Visual Image of Sun Wukong as an Example*
}

\begin{abstract}
WANG Daqiao
Lanzhou University, Gansu, China

As typical visual culture symbol of China, the visual image of Sun Wukong firstly appeared on the mural of Yulin Caves of Dunhuang in Western Xia regime and the story of Monk Tang and his prentices on the mural in Yuan Dynasty. Up to Yuan Dynasty, it became very popular. Since the novel Pilgrimage to the West was published, the visual image of Sun Wukong has appeared in the visual carriers of wood block, colored drawing, paper-cut, traditional Chinese opera, film, television, ad, cartoon and so on. European countries, America, Japan and South Korea use advanced film and TV technology and digital technology to deduce, model, adapt and simulate the visual image of Sun Wukong. This paper investigates the construction of the visual image of Sun Wukong in China and extraterritorial countries and regions, tries to explore Chinese "visual” experience in mediaeval times and especially modern times and seeks a clue for understanding Chinese problem of visual expression.
\end{abstract}

Keywords: Chinese visual experience, expression mechanism, Sun Wukong, visual image

Visual experience is not only a visual psychological activity at psychological level but also certain understanding on the world in the dimension of philosophy of culture. It is related to special aesthetical "experience" and world "view" of a nation. Different social types and different cultural types have different visual expression mechanism. Since Tang Dynasty, different historical stages of China and extraterritorial cultures have endowed the visual image of Sun Wukong with different features. Through investigating historical evolvement and extraterritorial construction of the visual image of Sun Wukong and analyzing image, lingual image, portrait, simulacra, simulacrum and phantom of Sun Wukong in cultural, artistic and literary production, the particular expression mechanism of Chinese visual experience can be elucidated.

\section{One}

Michelle emphasized that "any significant theoretical introspection on visual culture must narrate the historic significance of visual culture” (2006, p. 13). The visual image of Sun Wukong firstly appeared on the mural of Yulin Caves of Dunhuang in Western Xia regime and the story of Monk Tang and his prentices.

\footnotetext{
* Acknowledgements: This paper was sponsored by China National Social Science Foundation "Research on the Fundamental Problems of the Contemporary Aesthetics and Criticism Patterns” (15ZDB023).

WANG Daqiao, male, born in Shuyang, Jiangsu, Doctor of Literature, a professor in School of Literature of Lanzhou University with the research direction of aesthetic anthropology and aesthetics of Marxism.
} 
Monkey image was the ancestor totem of the Qiang people who lived their life on pasture. ${ }^{1}$ Diqiang culture on the only way which must be passed by Chinese-India cultural exchange made contribution to reconstructing the image of apes and monkeys in literary tradition of Han nationality. Based on this, Ye Shuxian thought that the cultural gene of monkey prototype of the image of Sun Wukong not only contained the factor of Sino-foreign cultural exchange but also contained the factor of domestic cultural interaction of multiple nationalities. The construction of monkey image witnesses the integration of Chinese culture ("Four-Evidence Method"). The visual image of Sun Wukong became very popular in Yuan Dynasty. Cultural Relics Institute Hebei Province reserves "Monk Tang going on a pilgrimage for Buddhist scriptures" cuboid pillow of Yuan Dynasty with black decoration on white ground. Both ends of its surface are drawn with dense and charming flower emblazonry. Internal pillow surface is drawn with the three figures of Pilgrimage to the West. The middle figure who rides on a horse is Monk Tang; the front figure who carries cane and baggage is Monk Sha; the back figure who holds golden cudgel and wears animal skin on waist is Sun Wukong. In 1972, a porcelain pillow of CiZhou Kiln of Yuan Dynasty was unearthed in Guangdong. ${ }^{2}$ The theme of the pillow was Monk Tang going on a pilgrimage for Buddhist scriptures. Four persons and one horse were travelling together. Sun Wukong was holding a golden cudgel with the posture of gallop. It appears that the "team" of four persons and one horse had finalized in Yuan Dynasty (Yang Zijian, 1987, p. 91). The surface contents of the porcelain pillows in Yuan Dynasty were mainly words and graphic patterns. The development of civic culture prompted CiZhou Kiln (folk kiln) to cater the taste of citizens. Folktales and Yuan poetic dramas were also drawn on porcelain pillows. On the pillows of Yuan Dynasty, the weapon of Sun Wukong was stick; the marshalling sequence of the three prentices was Sun Wukong (firstly), Pigsy (secondly) and Monk Sha (thirdly). This was same as the plot of the story of going on a pilgrimage for Buddhist scriptures. Being relative to the image of Sun Wukong in novel, the image of Sun Wukong on the pillows of Yuan Dynasty lacked stable brutish and deiform connotation.

In Pilgrimage to the West with one hundred chapters, more than ten descriptions on the image of Sun Wukong can be found. When the monkey was born from stone, "two golden lights shine from this eyes and radiate to the sky" (Wu Cheng'en, 1994, p. 2). When the monkey began learning skills, "his stature is shorter than four feet and he is younger than 30" (Wu Cheng'en, 1994, p. 24). He got "golden crown”, "golden armor”, "cloud shoes” and "golden cudgel” from the four Dragon Kings (Wu Cheng'en, 1994, p. 32). The appearance of Sun Wukong had not been completed eventually. The direct description on the portrait of Sun Wukong appeared in the $14^{\text {th }}$ chapter. Sun Wukong was suppressed under Five-Elements Mountain by Tathagata.

He has cuspate mouth, shrunken cheek and penetrating insight. Moss heaps up his head; ramblers germinate in his ears; little hair and lots of grasses grow at sideburns; there is no beard but bluegrass under his chin. Both eyebrow and nose are filled with dirt in so embarrassing situation. The fingers and palms become so thick with lots of dirt. He is still happy with rotary eyeballs and pleasant voice. (Wu Cheng'en, 1994, p. 152)

His short skirt made of skin of tiger and the kudzu vines at waist were got after he was saved by Monk Tang. "He held knife and cut the skin of tiger into two parts. After packing up one part, he wore the other part. Then he pulled a kudzu vine at road and bundled his waist to cover his lower part of the body" (Wu Cheng'en,

\footnotetext{
${ }^{1}$ In the $2^{\text {nd }}, 3^{\text {rd }}$ and $29^{\text {th }}$ cave of Yulin Caves and the $2^{\text {nd }}$ cave of Dongqianfo Caves, a mural was drawn: a monk put his palms together devoutly facing turbulent river. A prentice of monkey led an old horse. There was a forest in the distance. This prentice of monkey was said to be the earliest visual image of Sun Wukong.

${ }^{2}$ Front height is 11.5 centimeters; back height is 15 centimeters; length is 40.5 centimeters; width is 17.5 centimeters. Roughcast is bluish grey with white ground printing.
} 
1994, p. 154). Then Sun Wukong got "short and small frock made of white cloth" from Monk Tang (Wu Cheng'en, 1994, p. 156). Avalokitesvara conspired with Monk Tang to made Sun Wukong wear "admonition for tranquilization”, namely "the Incantation of the Golden Hoop” (Wu Cheng'en, 1994, p. 156). In this way, Sun Wukong got his own cap and the Incantation of the Golden Hoop. In the fourteenth chapter of the novel, the costumes and paraphernalia of Sun Wukong become complete. As for his concrete appearance, the novel wrote that: "like live Thunder God with grimace and fangs, sharp eyes and facial hair" (Wu Cheng'en, 1994, p. 209). In the eyes of common senior people, Sun Wukong is "a devil with oval face, whiskers, cuspate mouth and red eyes" (Wu Cheng'en, 1994, p. 225). In the eyes of monsters, Sun Wukong is "a monkey with wretched body, skinny appearance and the stature of less than four feet” (Wu Cheng'en, 1994, p. 235). In the eyes of Taoist, Sun Wukong is "a monk with round eyes, facial hair and cuspate mouth". In the eyes of monks, ugly Sun Wukong is "a monkey with bumpy face, two yellow eyes, a salient forehead and buckteeth like crab: flesh grows inside and bone grows outside” (Wu Cheng'en, 1994, p. 418). In the eyes of mortals, Sun Wukong is “a monkey with grimace and fangs, red face, a skirt made of skin of tiger and a golden cudgel held in hand standing under cliff like a live Thunder God” (Wu Cheng'en, 1994, p. 860). In short, the image of Sun Wukong described in novel is always "two parts of red face and one tail” (Wu Cheng'en, 1994, p. 873).

After the novel was published and issued, the visual image of Sun Wukong was performed, modeled, adapted and simulated in kinds of illustration, opera, folk arts and crafts, picture-story book, cartoon, film, television, advertisement, postage stamp and other visual texts. As for illustration, all the general versions of Pilgrimage to the West have illustrations. Shidetang version has 197 illustrations; Yangminzhai version has 1239 illustrations; Comment of Li Zhuowu has 200 illustrations; Zhenquan version has 20 tapestry portraits; Yuanzhi version has 8 tapestry portraits. The illustrations of Shidetang version are single large pictures. This was different from the type of "illustration up text" which was common at that time. In this design innovation, image of figures can be enlarged. Movement, postures and the five sense organs can be illustrated meticulously; the cuspate mouth and red cheek of the monkey can be illustrated completely and perfectly; facial feature, eyebrow, eyes and profile can be illustrated clearly. The abundant space can show complex background besides figure depicture. Zheng Zhenduo reviewed Yangminzhai version that "Yangminzhai version is depicted with illustrations up text; this is the book style of southern Fujian” (1998, p. 405). Yangminzhai version and Shidetang version almost establish the humanistic and animal image of Sun Wukong. In Comment of Li Zhuowu, Sun Wukong is thin and small with loose costume, walks like a cripple, holds golden cudgel reversely and twists his body. In the $14^{\text {th }}$ year of Guangxu of Qing Dynasty, Weiqianzhai issued Illustrations of New Pilgrimage to the West, containing 120 illustrations and 20 figure portrayals (Zhu Yixuan \& Liu Yuchen, 1983, p. 272). It depicts the cuspate mouth and red cheeks of monkey and especially portrays the penetrating eyes using meticulous brushwork. In Shidetang version and Comment of Li Zhuowu, Sun Wukong has bare head and wears costume without any peculiarity. However, in Illustrations of New Pilgrimage to the West, Sun Wukong wears a soft cap, skirt made of skin of tiger and a pair of boots. At the same time, some classical actions (such as jumping to and travelling on cloud, tightly holing golden cudgel and looking far into the distance gripping shack) in original versions are carried on as before. The humanity, godhood and animality of Sun Wukong gradually become clear in pictures.

Before the book of Pilgrimage to the West is completed, kinds of operas, manuscripts, poetic dramas and legends of "Pilgrimage to the West" appeared in past dynasties. Modern operas (no matter it is Peking Opera or Shao Opera) of "Pilgrimage to the West" inherit the spirit of the illustrations in printmaking of "Pilgrimage to 
the West" combining humanity and animality. The appearance of actors and actresses in costume and makeup inherits the freehand-style and symbolic-style drawing skills of Chinese facial makeup, refers to treatment method of folk New Year pictures, uses the drawing techniques of One Bell, Inverse Calabash and Inverse Peach Plantation with red alternating with white. Costumes of Sun Wukong are almost skirt made of skin of tiger and yellow coat armor. The image of Sun Wukong in printmaking excessively sticks to "facial hair and cuspate mouth" described in original work. It intentionally portrays the original details of the appearance of the monkey and depicts him to be a thin and small monkey with sinister appearance wearing loose frock. Although this pattern of manifestation is reasonable, it does not accord with the ideal expectation on the hero in audiences' mind. In money performance, the "handsomeness" of "Handsome Monkey King” is gradually enlarged and emphasized. The great influence of "Pilgrimage to the West" extends to modern drama, dance drama, puppetry and shadow puppetry.

In the folk arts of New Year pictures, murals, printmaking, colored drawing, paper-cut, paper-cut for window decoration, clay dolls, wood carving and stone inscription, the image of Sun Wukong can be found everywhere. With the help of powerful propaganda strength, cartoon and film and television make the visual image of Sun Wukong gradually become the important symbol of Chinese culture. In 1941, Wan brothers designed The Princess of Iron Fan. It was the first appearance of the image of Sun Wukong in Chinese cartoon. In figure modeling, Sun Wukong was designed to be an animal with facial hair and cuspate mouth according to the description in Pilgrimage to the West with one hundred chapters. Single lines were almost used to draw the image and curve was taken as the principal. In 1958, Wan Guchan designed Pigsy Eats Watermelon. He creatively animated Chinese traditional paper-cut to be animation. Sun Wukong evolves to be a monkey with humanity. In the 1960s, Wan Laiming directed Havoc in Heaven in which Sun Wukong evolved to be a hero combining the nature of human, immortal and monkey (Hu Ying, 2007, p. 103). The cartoon modeling of Sun Wukong in Havoc in Heaven is a nationalized prototype. As for the appearance modeling of Sun Wukong,

...it mainly refers to cute facial makeup of Peking Opera with humanistic features. The movement and form is similar with that of statues in temple—vigorous and smart. Lines drawing uses the method of wood printmaking—succinct and graceful. Color reflects the style of folk New Year pictures-sprightly and strong with the savor of decoration. Through summary and exaggeration, the stature features of wide shoulder, slim waist and long leg are shown. The common colors of red, yellow, black and green combine the lines filled with radian tension, which accords with people's aesthetic conception and shows the clear and positive traits of character. This is the classical image of Handsome Monkey King. Almost nobody transforms this image in several decades. (Guo Xiaohua \& Liu Wei, 2007, p. 107)

Monkey Surrenders Monsters and Ginseng Fruit in the 1980s, Lotus Lantern in the 1990s and Pilgrimage to the West with 52 parts shot by CCTV from 1998 follow the classical modeling of Sun Wukong in Havoc in Heaven. The visual image of Sun Wukong is almost confirmed in cartoon: yellow coat armor, skirt made of skin of tiger and the peach-shape face in the type of facial makeup in Chinese operas.

CCTV shot TV play series Pilgrimage to the West in 1986. The role of Sun Wukong was played by Liu Xiao Ling Tong. This play series perfectly combined monkey nature, humanity and godhood of Sun Wukong with the adaptation principle of "being faithful to original work and careful in refurbishment". In the play series, the modeling of Sun Wukong separated itself from the monster image with facial hair and cuspate mouth in original work and became Handsome Monkey King. Although Pilgrimage to the West has been adapted for many times and the video modeling of Sun Wukong emerges endlessly, the video image of Sun Wukong played by Liu Xiao Ling Tong has become a classical image. People tend to evaluate deviation degree of other 
images of Sun Wukong based on the modeling of Sun Wukong played by Liu Xiao Ling Tong. The cartoon Sun Wukong in Havoc in Heaven and true-person Sun Wukong in the TV play series Pilgrimage to the West shot by CCTV have gradually become the symbol of Chinese culture.

The members in the same culture must share kinds of series of concepts, images and ideas. The latter makes them think about and feel the world in similar methods and then explain the world. In short, they must share the same "cultural code”. In this significance, thoughts and emotions constitute "symbolic system” in our spiritual life. Our concepts, images and emotions are in this system. They represent and symbolize the live or "superlunary" matters. Likewise, in order to convey the significance to others, any participants of significance exchange must be able to use the same "language code". (Stuart Hall, 2003, p. 4)

As the "cultural code" of Chinese people, the visual image of Sun Wukong contains our emotions and significance. If the "cultural code" can be mastered and applied, it will be able to help us to confirm our national identity.

\section{Two}

As for how Sun Wukong began his extraterritorial travel, there is no method to restore it. The extraterritorial modeling difference of the visual image of Sun Wukong is actually the difference of aesthetic convention. As for the extraterritorial spread of Pilgrimage to the West, the east was earlier than the west. Its spread in the east had dense religious color. In Tang Dynasty and Song Dynasty, the story of Pilgrimage to the West in Japan was almost completed by monks. In Ming Dynasty and Qing Dynasty, large quantity of versions of Pilgrimage to the West were spread into Japan. Since the $20^{\text {th }}$ century, more than 30 Japanese translation versions have been created. Among the reasons why Pilgrimage to the West can be widely spread in Japan, the representative one is that China and Japan belong to the same Buddhist culture circle (Li Shunhua, 2001, p. 117). Since the $20^{\text {th }}$ century, with the help of mass media, Japan paid close attention to the story that Monk Tang went on a pilgrimage for Buddhist scriptures in the earlier stage. Later, it gradually became infatuated with the story that Monkey King fought against immortal beings and monsters. Through ceaseless adaptation in films, TV play series and cartoons, the visual image of Sun Wukong in the vision of Japanese culture was created.

Japan mainly created the visual image of Sun Wukong in cartoons. The image modeled in cartoons especially enjoyed popular support. Japanese cartoons appeared after the Second World War ended. The initial after-war cartoons were cheap reading materials for children. In this period, Japanese cartoons emphasized the monkey features (large head, small body, round face and round eyes) of Sun Wukong in the form of stick drawing of children. In the 1950s, Osamu Tezuka referred to the Sun Wukong modeling in The Princess of Iron Fan and Havoc in Heaven shot by Wan brothers and simply lowered the age of Sun Wukong. Jiang Qingqing thought that this was the main reason why Sun Wukong was popular among readers of Japan (Jiang Qingqing, 2008, p. 16). In the 1960s, Sun Wukong was modeled to be a Japanese boy. From his infancy in the 1950s, Sun Wukong entered into his adolescence. In the 1970s and 1980s, the modeling of Sun Wukong changed from mechanized youth appearance and humorous modeling with Japanese kimono to traditional cartoon modeling of Sun Wukong continued from Osamu Tezuka. Image features were very diversified. In the 1990s, "Japanese people took away the parts of Sun Wukong which they were interested in, integrated them into their own spiritual world and created kinds of new images” (Jiang Qingqing, 2008, p. 25). In initial stage of the $20^{\text {th }}$ century, Sun Wukong was abstracted and signified in high degree by Japanese cartoonists. The modeling was 
the common human image and costumes derived from Chinese tradition. At this time, Sun Wukong was imitated in large area. Osamu Tezuka's image of Sun Wukong was cartooned. The visual image of Sun Wukong was randomly changed. Countrymen were disgusted with that.

Before the book Pilgrimage to the West was completed, the introduction of Storytelling Pilgrimage to the West existed in the last phase of Korea (918-1392) (Jin Minhao, 2004, p. 199). According to the research of Song Zhenhe, since the 1980s, Pilgrimage to the West had offered abundant story plots, layout structure and figure roles to mass culture of cartoon, animation, electronic games, novels and so on. It was popular among Korean mass (Song Zhenhe, 2008, p. 239). It is noteworthy that the story of Monk Tang going on a pilgrimage for Buddhist scriptures and the novel Pilgrimage to the West are not the total sources of the visual image of Sun Wukong modeled by Korea. My Sun Wukong, Dragonball, SF Pilgrimage to the West, Pilgrimage to the East, Saiyuki and so on of Japan significantly influenced Korea. Dragonball was especially enjoyed by Korean adolescents. Cartoon of Pilgrimage to the West of Taiwan cartoonist Cai Zhizhong and Hong Kong film A Chinese Odyssey also influenced Korean mass. The familiar image of Sun Wukong in the mind of Chinese people wears golden hoop, holds golden cudgel and steps on somersault cloud. However, in animated film Fantasy Sun Wukong adapted from cartoon Mr. Sun, the golden hoop of Sun Wukong became helmet; the incantation of the golden hoop became the knock on wooden fish; golden cudgel became nunchakus; somersault cloud became skateboard. Wearing knee cap and hands cap, Sun Wukong was like a hip-hop juvenile who was playing skateboard. The Sun Wukong and plots in Magic Characters were used to improve children's ability of learning Chinese characters (Song Zhenhe, 2008, pp. 240-243). In serialized Pilgrimage to the West on Chosun Ilbo, Sun Wukong was not born in Water Curtain Cave of Mountain of Flowers and Fruits. He was born in the monkey crowd of Seoul Grand Park in Gwacheon of Korea. Sun Wukong woke up from anesthesia after he was confined in zoo for 500 days. The Korean elements carried by the image of Sun Wukong were based on considering domestic market of cultural products. In the opinion of An Zhenhe, the key of the success of cultural products is that cultural contents contain modern and global contents (Song Zhenhe, 2008, p. 249). Many reasonless humors in Fantasy Pilgrimage to the West and Legend offered happiness, catharsis and relaxation for readers.

Pilgrimage to the West was spread to Thailand by overseas Chinese. In the $19^{\text {th }}$ century, the Chinese characters in it were translated into Thai. The main overseas Chinese in Thailand were the immigrants from Fujian and Guangdong. Chaozhou opera became the broadest approach of spreading Pilgrimage to the West in Thailand. The Chinese immigrants in Thailand spread the story of Pilgrimage to the West to Thailand by Chaozhou opera. The latest time was the earlier stage of Qing Dynasty (Huang Hankun, 2004, pp. 53-54). In Chaozhou opera, the list of the parts of Pilgrimage to the West included The Mountain of Flames, The Birth of Sun Wukong, Sun Wukong Strives for Palm-leaf Fan for Three Times, Havoc in the Dragon King's palace, True and False Monkey King and so on. Sun Wukong was adored as a deity. This custom was spread to Thailand following Chinese immigrants. According to the survey of Thai Huang Hankun, Sun Wukong was enshrined in nine temples in Bangkok of Thailand. They are Mahatma Buddha Temple, Bulguksa Temple of Western Paradise, Mahatma Buddha Temple of Heavenly Palace Shengyuan Cave, Nanyang Buddhism Council, Hongyun Buddha Temple of Tianyun Altar, Qitian Palace, Yufu Hall, Hall of Goodness and Morality and Longlian Temple. Among the nine temples, three temples mainly enshrined Great Sage Equaling Heaven; the other six temples enshrined Great Sage Equaling Heaven as an affiliated sage (Huang Hankun, 2004, p. 55). 
The seventy-two metamorphoses, penetrating insight, somersault cloud and cloaking of Sun Wukong come from the novel. The Monkey King tells the story of Pilgrimage to the West in American culture. With the help of the existing story of Pilgrimage to the West, it sings a song for praising the American individual hero who rescues the world. In the film, Sun Wukong dresses up like an American West cowboy. He is the functional figure who pushes forward the development of plots. Costumes of players, scenes, props, musical instruments and so on contain Chinese cultural elements. This makes the rescue actions of Nick have the connotation of Chinese culture. The Sun Wukong in The Forbidden Kingdom is played by Li Lianjie. It deviates from the classical modeling of Liu Xiao Ling Tong because the film changes, shifts and anew configures the plots of Pilgrimage to the West.

British Broadcasting Corporation (BBC) made propaganda film Travel to the East for Beijing Olympics Games. This short film playing for 2 minutes uses background music with Chinese characteristics. Sun Wukong was born from stone and went on a pilgrimage with the guidance of Avalokitesvara. In his journey, he made the acquaintance of Pigsy and Monk Sha. They defeated all monsters depending on their Chinese Kungfu and the sports specialties of shot, hurdles, pole vault, horizontal bar, swimming and so on. Finally, they arrived at their destination-Bird Nest of Beijing. The creators of the short film are cartoonist Jamie Hewlett and rock singer Damon Albarn. They once issued a song with the theme of Pilgrimage to the West. While collecting folk songs in China, they said they loved Chinese culture. However, the propaganda film of "Sun Wukong goes on a pilgrimage to the east" causes a large dispute in China. The dispute point is whether the visual image of Sun Wukong and other figures deviates from the existing understanding of Chinese culture on the visual image of Sun Wukong. Its essence lies in whether Chinese aesthetic customs can accept the visual modeling of Sun Wukong in Travel to the East. In the short film made by BBC, the wild animal image of Sun Wukong is far from the image of Handsome Monkey King: cartoon image is the model of facial makeup of Peking Opera in Havoc in Heaven; true-person image is the Sun Wukong played by Liu Xiao Ling Tong.

The difference of the modeling of Sun Wukong actually reflects the difference between the aesthetic convention of China and that of Britain.

\section{Three}

The image, portrait, simulacra and phantom of Sun Wukong are presented in large quantity in drawings, films, dramas, cartoons, games and advertisements. They constitute a symbol with complex connotation. The visual text of Sun Wukong has activated the novel text in specific form. Literary text and visual text are jointly embedded into an expanded mutual text series. The image of Sun Wukong connects these texts. Business strategy, cultural policy, folk culture and ideology jointly constitute the movement field of the visual image of Sun Wukong. Contemporary people read the novel of Pilgrimage to the West with the visual image of Sun Wukong in their mind. Different image of Sun Wukong presents different mode of "viewing" the world and "experiencing" the world for the people in different time, at different hierarchy and in different culture. Barr emphasized that visuality indicated the possibility of the behavior of "watching" rather than the materiality of the "watching" objects (Wu Qiong, 2005, p. 15). Different time and different culture can endow the visual image of Sun Wukong with different connotation according to the existing aesthetic convention.

If convention is thought about as a comprehensive phenomenon, its diverse appearance does not influence our descriptive recognition on it: the common tendency or habit of people's behavioral pattern formed in the 
inheritance in certain social crowds is called convention. ${ }^{3}$ Convention is a constraint force. It can decrease the tendency of mutual difference, model them to be similar and arrange their life. In the opinion of Montaigne, beauty is interest. "we imagine that its form accords with our fantasy" (The Big idea of the West, 2008, p. 216). The interests or preferences of a crowd are often opposite to the interests or preferences of another crowd. This is unreasonable. Convention models experience and behaviors of people. It also restricts and regulates people's mode of "viewing" the world and "experiencing" the world. Convention contains experience of the crowd while habit forms from the repetitive accumulation of personal experience. Human's perceptual experience or emotional experiencing mode is contained in convention. Traditional anthropologists captured the characteristics of conventional culture depending on public ceremony, symbolic novel system and conventional family or community structure. The concern for experience of convention and human's emotional experience is not enough. Individual, ego and emotion are the problems which are difficult to be reflected in traditional ethnography structure. "Local knowledge" of Geertz emphasized the endemicity of convention. Aesthetic convention links local aesthetic experience. It guides and restrains the aesthetic experience of certain group. And it can be influenced by local production mode and cultural contents.

If visual art is really a "symbol system” filled with “convention” just as Michelle said before (Michelle, 2006, p. 15), the understanding on visual text of Sun Wukong shall ascend to the aesthetic habits constituted by visual experience. As for the research on the internal convention difference of culture, Bourdieu brought enlightenment to us. He realized that non-negligible relation existed between social transition and individual temperament (Jeremy F. Lane, 2000, p. 47). In the opinion of Bourdieu, as a prominent manifestation of cultural character, interest is a key separation symbol of integral class habit. The formalism explanation on work of art required by interest obliterates the social conditions interest depends on, especially the relation between interest and education system and the relation between interest and class habits. As an aesthetic custom, artistic convention can achieve the integral experience communication between artists and recipients. This communication achievement is determined by sharing the same emotional structure. Williams thought that:

...in realistic practice of drama, convention is purely the terminology of author, performers and the public agreeing to meet in any special situation. Based on this, the performance can continue. Agreement on meet is not always a formal or certain process. In any art, this consent is usually customary and unconscious in fact. (Raymond Williams, 1981, p. 4)

If artistic work is the pattern of emotional structure, artistic method corresponds to certain emotional structure and promotes and strengthens the emotional structure through artistic works. So this method is called new convention and custom. "All transitions of a artistic method link with the essential emotional structure transition of human. This is the premise of artistic analysis and research on a stage” (Liu Jin, 2007, p. 389). As the formalization of experience, art can be expressed with the "emotional structure” presented by works of art through artistic convention or aesthetic custom. The premise of the change of artistic convention or aesthetic custom is the change of emotional structure.

The internal cultural difference and belligerence of cultures determine the complexity and mobility of

\footnotetext{
${ }^{3}$ Custom can be understood to be the mixture of many different phenomena, such as habit, habitus, manners and conventions. Custom conserves experience of ethnic group; habit is the repetitive accumulation of individual experience. Human's perceptual experience and emotional experience modes are contained in custom. Aesthetic custom links with local aesthetic experience. It guides and restrains the aesthetic experience of specific ethnic group. And it is influenced by local production mode and cultural contents.
} 
emotional structure. "Cultural misunderstanding" is the typical symptom when different cultures mutually encounter. "The residents in the jungle of Australia cannot recognize the theme of The Last Supper. As for them, this painting only expresses an exciting dinner party” (Peter Burke, 2008, p. 44). In animation field, Japan and Korea take the vantage in the exchange and cultural communication with China with the assistance of the visual image of Sun Wukong. Hollywood modified the visual image of Sun Wukong. Imaginary understanding on Chinese culture in The Monkey King cannot get rid of the value standpoint of "west centralism”. In cross-cultural communication, art can remit the sense of tension brought by cultural misunderstanding. The description and symbolization on "Chinese aesthetic experience" or "local aesthetic experience" is an effective approach for decreasing cultural misunderstanding.

"If significance is not the result of certain fixed matter in essence but the result of social, cultural and linguistic convention, significance will not be fixed forever" (Stuart Hall, 2003, p. 24). Verbal icon and image structure the symbol of Chinese culture-Sun Wukong. The visual symbol of Wukong has indeterminate meaning. The visual image of Sun Wukong established by extraterritorial nations inevitably carries local color. In Chinese cultural context, the local color in aesthetic image modeling is even clear. No matter how intense local color is, the visual image of Sun Wukong is a practice symbol and an image symbol about the sense of national ascription. As an aesthetic symbol which symbolizes Chinese culture, visual image of Sun Wukong

...is a product of special social custom system as for each society and each historical stage. All significances are produced in history and culture. They will never be determined and always be enslaved to change. They change between a cultural context and another and change between a stage and another. Therefore, simplex, immutable and common "real significance” does not exist. (Stuart Hall, 2003, p. 32)

In the process of reconstructing diverse visual image of Sun Wukong, aesthetic custom will be the most powerful restriction.

\section{References}

Chen Jiaying (Trans.). (2008). The Big Idea of the West (the first volume). Beijing: Huaxia Publishing House.

Guo Xiaohua \& Liu Wei. (2007). Cartoon Art and Works Appreciation. Beijing: Higher Education Press.

Hu Ying. (2007). Unswerving Sun Wukong Complex_-Preliminary Exploration on Animation Design Thoughts of Wan Brother.

Journal of Guangxi Arts University, (4).

Huang Hankun. (2004). The Spread and Influence of Pilgrimage to the West in Thailand. Classical Literature Knowledge, (4).

Jeremy F. Lane. (2000). Pieer Bourdieu. London: Pluto Press.

Jiang Qingqing. (2008). Differentiate and Analyze the Sun Wukong in Japanese Cartoon (Master's thesis of Chongqing University).

Jin Minhao. (2004). Pilgrimage to the West in Korea. Research on Novels of Ming and Qing Dynasties, (1).

Li Shunhua. (2001).The East and the West: Pilgrimage to the West in Extraterritorial View. Academic Exchange, (1).

Liu Jin. (2007). Literature and "Cultural Revolution”: Literary Criticism Research on Raymond Williams. Chengdu: Bashu Publishing House.

Peter Burke. (2008). The Uses of Images as Historical Evidence. (Yang Yu, Trans.). Beijing: Peking University Press.

Raymond Williams. (1981). Drama from Ibsen to Brecht. New York: Penguin Books Ltd.

Song Zhenhe. (2008). Pilgrimage to the West in Korean Mass Culture. Research on Novels of Ming and Qing Dynasties, (4).

Stuart Hall. (2003). Representation. (Xu Liang, Trans.). Beijing: The Commercial Press.

W. J. T. Michelle. (2006). Theory of Image. (Chen Guoyong, Trans.). Beijing: Peking University Press.

Wu Cheng'en. (1994). Pilgrimage to the West. Nanjing: Phoenix Publishing House.

Wu Qiong. (2005). The Marvelous Spectacle of Visual Culture. Beijing: China Renmin University Press.

Yang Zijian. (1987). Detailed Explanation on Wu Cheng'en Pilgrimage to the West. Journal of Nankai University (social science edition), (4). 
Ye Shuxian. (2010). Four-Evidence Method: Reconstruct Chinese Cultural Perspective in Semiology View. Guangming Daily, July 17.

Zheng Zhenduo. (1998). Evolution of Pilgrimage to the West. Explanation on Pilgrimage to the West. Jinan: Shandong People’s Publishing House.

Zhu Yixuan \& Liu Yuchen. (1983). Compilation of Materials About Pilgrimage to the West. Zhongzhou: Zhongzhou Calligraphy \& Painting Publishing House. 